\title{
The Significance of Using 'Expert System' to Assess the Preparedness of Training Capabilities against Different Flash Flood Scenarios
}

\author{
M. Hijji, S. Amin, R. Iqbal, and W. Harrop
}

\begin{abstract}
Having an effective disaster management response capability is central to managing civil defense requirements in Saudi Arabia. This paper evaluates the significance of introducing an Expert System (ES) to help support, measure, and improve training and preparedness capabilities of the Saudi Arabian Civil Defense Authority. This paper evaluates the disaster training capabilities, and preparedness needs following many recurrent flash flooding events in Jeddah and Mecca. This paper proposes an ES that could help anticipate, evaluate and improve civil defense flash flood training capabilities against scalable flash flooding risks identified at a local level in Jeddah and Mecca.
\end{abstract}

Index Terms-Expert system, knowledge-based system, emergency management system, training capabilities, flood management.

\section{INTRODUCTION}

It is crucially important to have adequate and demonstrable disaster management capabilities in place such as training capabilities -which is the discussed area in this paper- to ensure an effective disaster management response to and recover from various scenarios of disaster. It is human nature to make mistakes, and poor decisions by decision-makers could divert organizations from the targeted standards for training capabilities as a result of 1 ) a lack of experience, 2) pressure, 3) a lack of overall vision related to the gaps in training capabilities for emergency responders, or 4) a lack of information from other parties [1]. However, with the continued development of Information Technology (IT), it could be effective to create an ES to digitalize the processes of 'identifying the targeted standard for training capabilities for emergency-responder' and 'evaluating the preparedness of the current training capabilities against the upcoming disaster' in a central ES. The ES can provide decision-makers and stakeholders with assurance and can recommend local and regional training capabilities for emergency responders before, during, and after a disaster. Adequate training is the cornerstone of effective emergency response [2], as an emergency responder with effective training will be able to understand and assess risk, plan responses, use the right types of equipment and apply the proper national and local emergency management policies and procedures [3]. In this

Manuscript received April 29, 2014; revised July 28. 2014.

M. Hijji, S. Aimn, and R. Iqbal are with Engineering and Computing Faculty, Coventry University, UK (e-mail: hijjim@ coventry.ac.uk, s.amin@coventry.ac.uk, r.iqbal@coventry.ac.uk)

W. Harrop is with Faculty of Business and Environment, Coventry University, UK (e-mail: w.harrop@ coventry.ac.uk). paper, the aspect of training capabilities in the Civil Defense Authority in SA will be highlighted; also the training capabilities will be examined against various flash-flood scenarios in Jeddah. The proposed ES in this paper will only address the part of the training capabilities. However the research and the proposed ES will cover other areas of capabilities such as Human Recourses (HR) and equipment.

\section{BACKGROUND TO CASE STUDY AND ISSUE}

The Civil Defense Authority of SA is responsible for responding to a natural disaster, it has been facing significant criticism about its ineffective management against flash-flood events in precarious locations on a floodplain, such as in Jeddah city [4], [5], which is part of the Mecca region and suffers from repeated flash-flood events due to its geographical and topographical characteristics [6]. As you can see in Table I, a number of flash-flood events occurred between 1964 until 2014.

TABLE I: THE ARRANGEMENT OF CHANNELS [7]

\begin{tabular}{lcll}
\hline \hline City & Year & $\begin{array}{l}\text { Number of } \\
\text { people killed }\end{array}$ & $\begin{array}{l}\text { Number of } \\
\text { Affected people }\end{array}$ \\
\hline $\begin{array}{l}\text { Several parts of the } \\
\text { country }\end{array}$ & 1964 & 20 & 1,000 \\
Northwestern & 1985 & At least 32 & 5,000 \\
Jizan & 2004 & 5 & 430 \\
Mecca & 2005 & 29 & 17 \\
Jeddah & 2009 & 163 & More than 10,000 \\
Jeddah & 2011 & More than 10 & 144 \\
Tabuk & 2013 & Unvalued Data & Unvalued Data \\
Mecca & 2014 & Unvalued Data & Unvalued Data \\
\hline \hline
\end{tabular}

Several issues were indicated across research as effective reasons why processes involved in disaster management may have been less effective, such as 1) high illiteracy rates in affected populations [8], 2) a lack of coordination between the Civil Defense Authority and other governmental partners and 3) structural issues related to absent of sirens and inadequate electronic mapping of the affected cities (which has recently been addressed) [5]. An interesting statistical study published by the Civil Defense Authority in 2007 [7] highlighted that, there is a remarkable number of emergency-responder injuries in the Mecca region when compared with other regions, including the largest region, Riyadh, this study could be linked to another study conducted in 2009, where its findings criticized the functional capabilities of many Middle Eastern countries (including SA) mainly due to insufficient emergency training capabilities [9]. This research paper continues to find there is limited training 
provision allocated to frontline emergency responders. One area of significant concern is the ability of emergency responders in Jeddah and Mecca to meet current and future flash-flood events, and in adequate investment in managing flood related community vulnerabilities. There is need to improve flash flood training capabilities Having an effective emergency response capability is central to managing civil emergencies within community settings1. This paper identifies the significance of introducing an Expert System (ES) to help support emergency responder capabilities in the cities of Jeddah and Mecca. The purposeful intent of the ES is to introduce a frontline emergency preparedness and electronic training tool designed to forecast needs against a range of scalable flash flood events as identified by field research [8].

All of these issues are came out or considered under the ineffective activation and integration of two major frameworks which are: 'the Preparedness Cycle' and 'the Disaster Management Cycle' (see Fig. 1 and 2 below). The Preparedness Cycle is a framework developed by the Federal Emergency Management Agency (FEMA) that aims to "ensure effective coordination during incident response, through a continuous cycle of planning, organizing, training, equipping, exercising, evaluating, and taking corrective action" [10]. On the other hand, the Disaster Management Cycle is "a cyclical and collaborative process spanning four critical disaster phases of Mitigation, Preparedness, Response and Recovery" [11], and each phase needs specifically targeted capabilities tied to specific outcomes[10]. The preparedness Cycle is actually the basis for developing and maintaining the training capabilities across the phases within the Disaster Management Cycle [9].

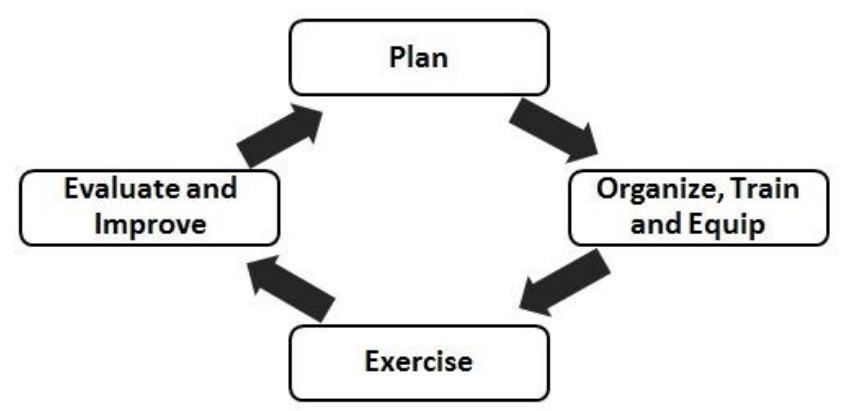

Fig. 1. Capabilities preparedness cycle [10].

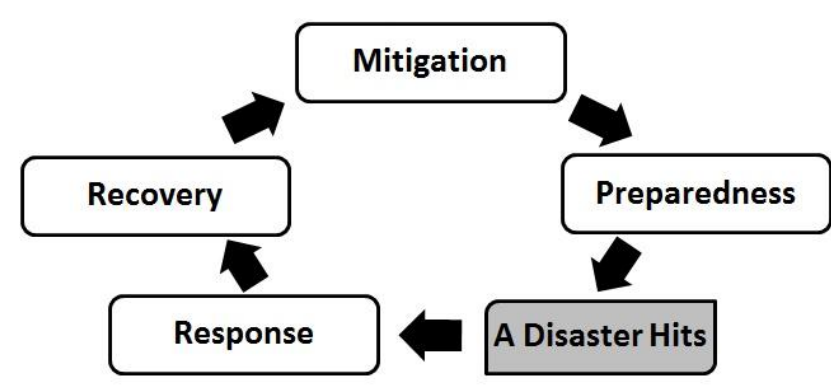

Fig. 2. Disaster management cycle [10].

The difficulty and challenge for the Civil Defense Authority and any organization in applying these frameworks is focused on two aspects which are:

1) Knowing thoroughly the answers of three issues 1) How prepared are the training capabilities of emergency-responders? 2) How prepared do training capabilities of emergency-responders need to be, in order to overcome various anticipated scenarios of Flash-flood event(s)? and 3) Prioritizing efforts to fill the major gaps [10].

2) The activity of the Capabilities Preparedness Cycle in the Civil Defense authority regarding the aspect of training capabilities; is it a reacting framework conducted due to a disaster that has happened ? or active framework dealing with the continuous changes related to internal and external factors such as knowledge and skills gaps against the vulnerabilities and strength of flood [12].

There is not sufficient research about the assessment of preparedness of the training capabilities for emergency responders in the Civil Defense Authority of SA; hence, this research includes a field study conducted to evaluate the current training capabilities at the Civil Defense Authority in two distinguished cities in SA: Jeddah and Mecca. This study will help to evaluate the rational need for a proposed ES which might contribute on the mentioned points previously.

\section{ASSESSMENT OF TRAINING CAPABILITIES}

To clearly demonstrate the demand for the proposed ES, a field study was conducted to assess the current training capabilities regard to handling various levels of flash-flood events: low, medium and high flash-flood events. This field study targeted emergency-responders and decision-makers under the authority of Civil Defense Authority in Jeddah and Mecca location within SA. A questionnaire and an interview were used to collect the primary data from the participants.

The estimated levels of anticipated flash-flood events were estimated and mapped based on primary data that were collected in an interview with the Saudi Geological Survey's Flood Disaster Department. The estimates of the anticipated flash-flood events took into account a) the previous history of flash-flood risk and b) the records of 50-100 years of rainfall intensity. The estimates levels of flash flood events are created only for one city; which is Jeddah.

The collected primary data from the questionnaire represent the views of two hundred emergency responders chosen randomly from various centers in Jeddah and Mecca. The views of decision-makers in the Civil Defense Authority were also taken into account via interview to compare the views and to obtain a clear and coherent assessment alongside the primary data. The assessment criteria were significant aspects of the mission during flash-flood management: prevention, protection, response, and recovery.

This assessment is not aimed at critically analyzing the flash-flood management capabilities of the Civil Defense Authority in SA, but rather it attempts to identify and address the fact that there is a lack of effective usage of the Capabilities Preparedness Cycle including the predictions regarding the required training capabilities with regard to scalable levels of flash-flooding. Also more intriguingly, it evaluates the training capabilities of Mecca's emergency responders which is significant if a case of mutual-aid occurs. The evolution of this aspect will also contribute to have a clear comparison regarding the training capabilities 
preparedness among both cities against the same risk.

\section{A. The Likelihood of Injuries and Operational Failure}

This section addresses 1) whether the training provided helps to decrease the likelihood of staff injuries and 2) whether the training provided helps to decrease the likelihood of operational failure. Data collected from emergency responders showed a variance in answers regarding knowledge of these areas (see Fig. 3 below). The results for Jeddah showed negative responses, and the weighted means for both items was found to be 2.33 and 2.32, respectively, which aligned with "Disagree" in the results of questionnaire answers. However, Mecca's results showed a lower proportion for both items, as the calculated weighted mean for the responses resulted in a "Neutral" outcome.

The Civil Defense Authority provides several refresher training courses for emergency responders and found no fault in their duties. However, two corporals from Civil Defense Authority who were interviewed, in Jeddah and Mecca, both mentioned that the knowledge delivered in these refresher training sessions was not related to flash-flood responses. The corporals recommended upgrading and improving the context, quality, and implementation of refresher training. With regards to injuries, both corporals mentioned the need for physical rehabilitation due to the issue of body-weight gain. The findings in this section indicate that there is a lack of training towards this issue especially in Jeddah emergency responders.

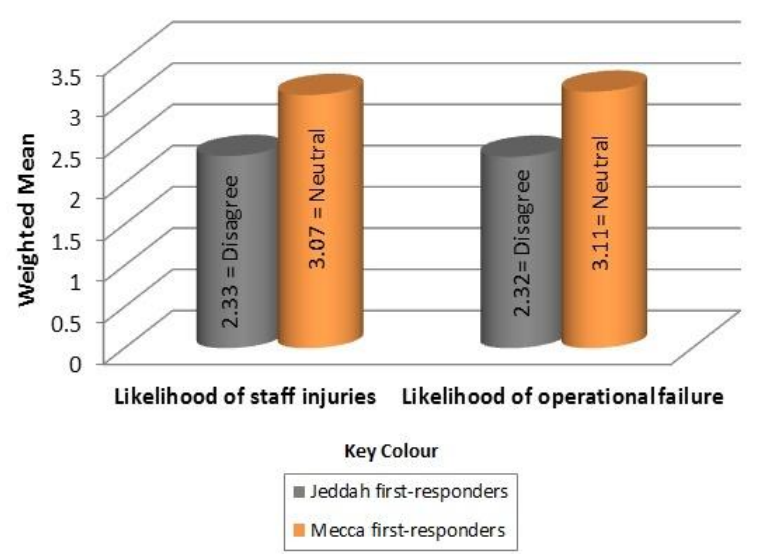

Fig. 3. Assessment of areas wihtin training capability (2013).

\section{B. The Appropriateness of Training Provisions for Co-Workers, External Co-Workers, and Volunteers}

This part of the questionnaire reviews the opinion of emergency responders based on their observations during their duties regarding whether 1) co-workers, 2) external co-workers, and 3) internal volunteers received appropriate training for responding to flash-flood events. An analysis of these items showed that there was agreement between the responses from Jeddah and Mecca (see Fig. 4 below). The results for Jeddah and Mecca demonstrate negative outcomes for all items in relation to stakeholder training. The data provided by Jeddah's emergency responders provided interesting results with regard to the appropriateness of the training received by their co-workers, as the weighted mean of this item was found to be 1.74, which aligns with "Strongly Disagree." However, their views of external co-workers and internal volunteers were less negative, as the weighted means were found to be 1.9 and 1.89 , respectively, which align with "Disagree" rather than "Strongly Disagree.".

Regarding Mecca's responses, the results were also interesting, as the emergency responders in Mecca had less negative responses with regard to the appropriateness of the training received by internal volunteers than for the appropriateness of the training received by external co-workers. The responses align with "Disagree" for internal volunteers and align with "Strongly Disagree" for external co-workers.

The Civil Defense Authority provides training for external co-workers and internal volunteers. According to the Head of the Civil Protection Department in Mecca, the training provision considers everyday operations activities rather than specific activities related to flood disaster, unless the trainer has an interest in teaching it. Two sergeants from Civil Defense Authority mentioned that there was a lack of knowledge about flash-flood risk. In particular, there was a need to provide training on rescuing people and dealing with floods for some emergency responders. The sergeants also highlighted the need to increase awareness, especially among citizens who have difficulty reading and writing. This group appears to lack awareness and respond weakly to orders issued by emergency responders. The two sergeants recommended that training be provided to handle these risk factors. The findings in this section reflect that there is a major lack of training addressing this issue across various types of emergency responders in Jeddah and Mecca.

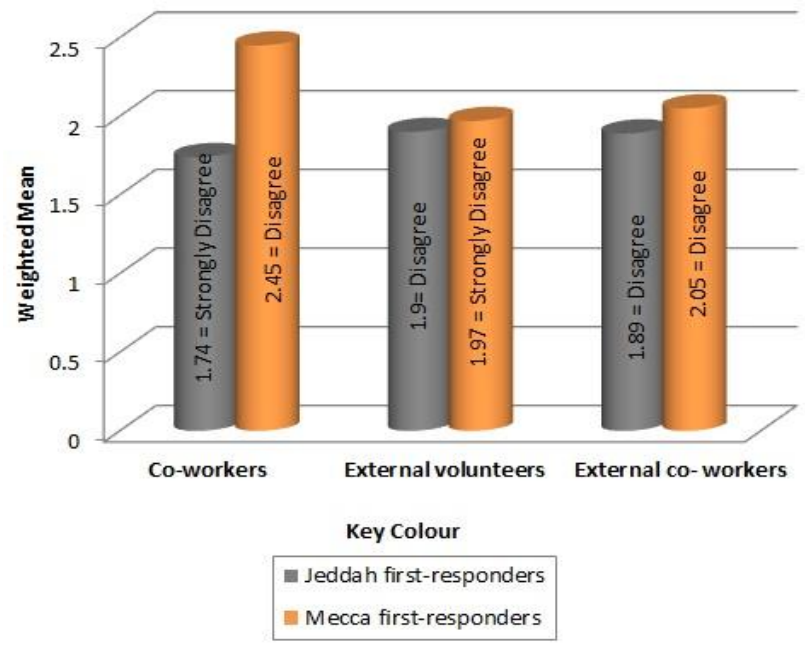

Fig. 4. Assessment of areas wihtin training capability (2013).

\section{Overall Training Capability with Regard to Scalable Levels of Flash Flood Events}

The analysis of this section of the questionnaire provides an overview assessment of the gaps within the training. The emergency responders were asked if the received training would allow them to cope with the various levels of flash-flood risk. The results indicate a negative outcome: "Disagree" and "Strongly Disagree" based on the weighted means (see Fig. 5 below). The results showed that Jeddah and Mecca's answers were similar in terms of agreement, which was expected according to the outcomes of the previous finding. The responses from Jeddah aligned with "Disagree" 
with regard to level one flash-flood events, which is less than the impact of the Jeddah flash flood in 2009. On the other hand, the responses from Mecca were neutral with regard to level one flash-flood events. For level two flash-flood events, which was the level of the Jeddah flash flood in 2009, the results showed negative responses for both cities, where the calculated weighted means were 1.89 and 2.11 , respectively, which both align with "Disagree." Finally, regarding level three flash-flood events, which is double the impact of the Jeddah flash flood in 2009, the results portrayed highly negative outcomes for both cities: "Strongly Disagree" based on the weighted means.

This was a debated point during the interviews with decision-makers from the Civil Defense Authority, where many decision-makers admitted the difficulty of providing the needed training for individuals based on risk factors within an area and the level of risk for a flash flood. On the other hand, few decision-makers adopted the view that the method of training via everyday incident operations is the most effective and virtual method. However, there are major differences between everyday incident operations, which is a normal mode, and disaster operations, which requires emergency responders to switch to a crisis mode, and the variances in their impact on the environment, the people, and the infrastructure could impede the effectiveness of emergency responders if they have not received adequate training in the area of flash-flood response.

According to the findings above, it seems that the current implantation or employment of the Preparedness Cycle in relation to training capability, does not contribute to effectively providing the required training courses for individuals to meet the current and future risk and risk factors within an area. Hence, this research attempts to prove the significance of using an ES as a management tool, in the context of disaster and emergency management, for evaluating and providing effective training to emergency responders to meet the current and future flash-flood risk.

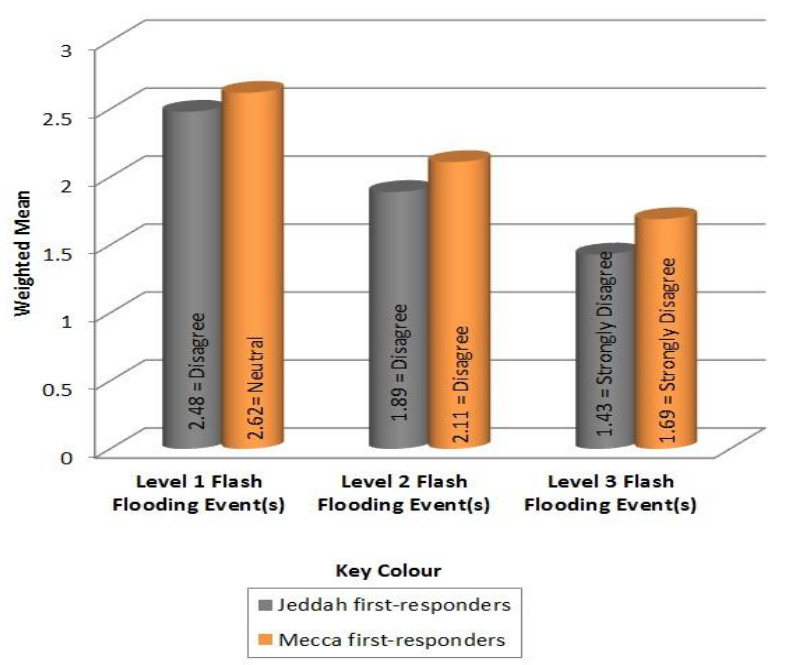

Fig. 5. Assessment of the overall training capability (2013).

\section{BACKGROUND TO THE USE OF IT/ICT SYSTEMS IN DISASTER MANAGEMENT}

Many virtual IT/ICT systems are used in Disaster Management Cycles. In terms of the mitigation phase,
IT/ICT systems have been widely integrated into the Global Information System (GIS) to map and assess flood risk, and interactive games and simulation systems are used to educate, test, and assess emergency-responders through the visualization of 3D flood scenarios [13], [14]. Collaborative/e-government systems are used to record and share information related to risk and to provide reports and statistics [15].

In terms of the preparedness phase, IT/ICT systems have been widely integrated into Wireless Network Sensors (WNS) and telecommunication technologies, such as mobile and social networks, to create an early warning framework that can track the direction of floods.

In terms of the response phase, the use of a disaster recovery system has become increasingly significant for protecting the IT/ICT system to ensure that it is available during a disaster.

In terms of the recovery phase, integrating a global positioning system (GPS) or radio frequency identification (RFID) technologies into an IT/ICT system can contribute to directing emergency responders and first-aid providers during the rescue process. Furthermore, there are some IT/ITC systems that can be used across all phases of the Disaster Management Cycle, such as an expert system or a decision support system, and these types of system can solve issues that occur before, during, or after a disaster in the most effective way.

Although the use of IT/ICT systems in disaster management has continually evolved, there is little known about the use of an IT/ICT system to evaluate and address the training needed for disaster management in relation to current and future flood risks. There are only theoretical frameworks with regard to this aspect. The most commonly used framework was developed be FEMA, as mentioned before, and this framework contributes to building effective training capabilities for emergency-responders with regard to prevention, protection, response, and recovery.

The framework consists of four phases: 1) plan, 2) organize, train, and equip, 3) excise, and 4) evaluate and improve. There are two major processes involve in this framework: a) analyzing various expected risk scenarios and b) identifying the capabilities needed to be effective in managing the risk scenarios. When a potential challenge is raised, according to a number of studies, most organizations and governments find it difficult to anticipate and address the capabilities needed and struggle to answer the question "How prepared do we need to be" [7], and this is because of the complexity of the risk scenarios, mission aspects, and capabilities needed. As a result, it can be concluded that the more ineffective the decisions made across these processes, the weaker the overall training capabilities will be across the mission areas (prevention, protection, response, and recovery). The findings of the field study on Civil Defense Authority in SA show potential outcomes that could arise due to the lack of analysis or decision-made across the framework.

Therefore, this research will examine and test the use of an IT/ICT system to anticipate effective training capabilities for various mission areas with regard to responses to scalable flash-flood events the Civil Defense Authority in SA. 


\section{The Proposed Prototype ES}

ES is defined as "A system that is largely a collection of heuristic rules and detailed domain facts that have proven useful in solving the special problems of some technical field" [16]. This type of system has been chosen because of its ability and its relevance with regard to solving issues discovered in a field study, as ES is able to provide effective discussion about the required preparedness in the training capabilities for the various flash-flood scenarios. The proposed ES will be designed to helping end-users to address effectively the mentioned issues; 1) How prepared are the training capabilities of emergency-responders?, 2) How prepared do training capabilities of emergency-responders need to be to overcome various anticipated scenarios of Flash-flood event(s)? and 3) Prioritizing efforts to fill the major gaps [10]. The ES also will be designed to be a centralized ES, to collaborate with various emergency stakeholders and collect the internal and external data and factors as changeable inputs, then analyze these data in order to reach an activate mode of the assessment of the preparedness related to training capabilities against various levels of flash-flood events. The components of the prototype ES will be demonstrated in detailed as the following:

\section{A. Knowledge Base}

This section of the system, as shown in Fig. 7, will store all the data, information, rules, cases, and relationships:

1) Training courses and their mission areas.

2) The training and evaluation received by emergency responders with regard to each mission area.

3) The location of emergency responders based on the location of each center of the Civil Defense Authority.

4) Risk assessment for each area, including the size of each flash-flood scenario and the vulnerability such as disabilities, traditional house, illiterateness, population density.

5) Standards or rules for the training capabilities needed for each flash-flood scenario while also taking into account the vulnerabilities within each area, illiterateness.

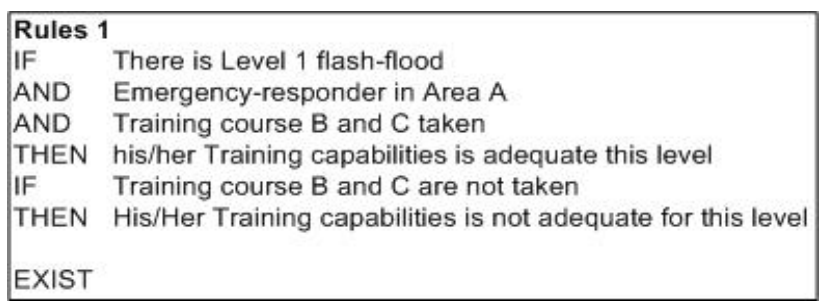

Fig. 6. Sample of a rule used by the interface engine.

This information will be used by the ES to solve problems related to identifying and assessing training capabilities with regard to the scalable flash-flood scenarios and to understanding where the training capabilities are and where they need to be. This warehouse of information will be captured from human experts in Emergency and Disaster Management and in Risk Assessment of Flash Floods. Some of the knowledge base will include factual knowledge (such as the standards or rules for the training capabilities needed for handling people with disabilities) and heuristic knowledge (such as the training and evaluations that have been received).

\section{B. Knowledge Base Acquisition}

Knowledge-base acquisition is considered a subsystem in the prototype ES and it aims to obtain the documented knowledge sources (such as training records) and experts' experiences regarding the management of flash floods (such as risk assessment and the targeted standards for training capabilities) and to transfer these into the knowledge base section. Knowledge-base acquisition is a subsystem that will help in the construction of the knowledge base.

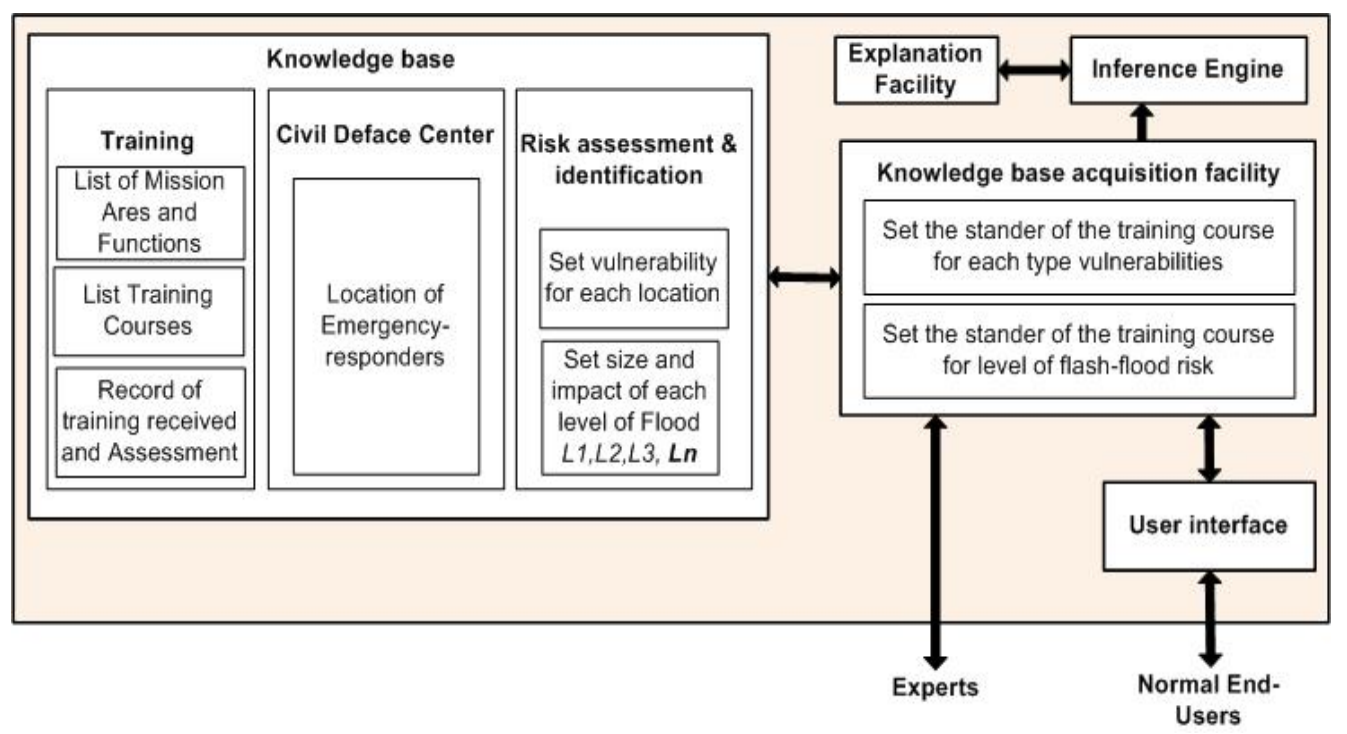

Fig. 7. A framework of the components of the prototype ES addressing the aspect of training capabilities.

In order to produce an effective ES with voluble outcomes, the knowledge-base acquisition subsystem will be designed to be a collaborative IT system, and once it obtains the required data and information, it will help the ES to provide the most adequate and effective outcomes.

\section{Interface Engine}

This is the core of the analysis, predictions, and suggestions in the ES, and it will process all data and information related to training capabilities that is stored in the 
knowledge base using the set rules and methodology. The interface engine is the engine that will use the rules to provide the outcomes: 1) identification and notification of the training capabilities needed to manage the anticipated flash-flood events 2) and determination of whether the current training capabilities are adequate for managing a flash-flood event that event that have been warned against.

In order to have an effective ES, it is important to make sure that the ES provides the outputs according to the approach that a human expert in disaster management would take [11]. In this way, the ES will provide the reasons for the given outcomes. Fig. 6 shows an example of the engine's process in the ES.

\section{User-Interface}

Through the user-interface, the end-user will be able to communicate and interact with the proposed system. During the process of designing the user-interface, the graphics and template will be carefully considered with regard to the context of The Civil Defense Authority in SA. The design of the user-interface and how the ES deals with the end-user are significant in terms of presenting the outcomes in a way that leads to effective understanding.

\section{Methodology}

In this research, the adopted methodology was based on Kumar's research framework methodology, which is applicable to IT/ICT research [17]. The tools used to represent the results of the field study were IBM SPSS and Microsoft Office Excel. The system was designed using Visio, and it will be implemented using simulation tools. The Story-Board method will be used to design the system's interfaces and sequence.

\section{CONCLUSION}

The results of the field study positively indicated the need for the proposed ES in SA in order to improve the process of identifying and evaluating the required training capabilities with regard to various flash-flood scenarios. The proposed ES is currently in the design phase; however, it will be implemented as a prototype and evaluated in the Civil Defense Authority in SA, in order to modify the system to ensure applicability within the SA context.

\section{REFERENCES}

[1] R. H. Flin, P. O'Connor, and M. Crichton, Safety at the Sharp End: A Guide to Non-Technical Skills, Ashgate Publishing, Ltd., 2008.

[2] M. E. Jennex, "Modeling emergency response systems," in Proc. 40th Annual Hawaii International Conference on System Sciences, 2007, pp. 22-22.

[3] M. S. Kumar, S. Sindhi, H. Dhanze, and A. Prasad, "Overview of disaster management," Role of Veterinarians in Disaster Management, Food Safety and Control of Zoonotic Diseases, p. 123, 2013.

[4] N. M. Momani and A. S. Fadil, "Changing public policy due to Saudi City of Jeddah flood disaster," Journal of Social Sciences, vol. 6, p. 424, 2010.

[5] S. S. Abosuliman, A. Kumar, F. Alam, and R. Rasjidin, "Disaster planning and management in Jeddah, Saudi Arabia," in Proc. 2013 International Conference on Economics and Social Science (ICESS 2013), Melbourne, Australia, Jan.20-21, 2013.

[6] W. Solecki, R. Leichenko, and K. O'Brien, "Climate change adaptation strategies and disaster risk reduction in cities: Connections, contentions, and synergies," Current Opinion in Environmental Sustainability, vol. 3, pp. 135-141, 2011.

[7] General Defense of the KSA. (March 10, 2007). Civil Defence: Number of Injuries Staff. [Online]. Available: http://www.998.gov.sa/Ar/Pages/Default.aspx

[8] Y. Alamri, "Emergency management in Saudi Arabia: Past, present and future," Un. Of Christchurch report, New Zealand, p. 21, 2010.

[9] S. Deneulin and L. Shahani, An Introduction to the Human Development and Capability Approach: Freedom and Agency: Earthscan, 2009.

[10] Federal Emergency Management Agency (FEMA). (March 31, 2013). National Preparedness Cycle. [Online]. Available: http://www.fema.gov/national-preparedness-cycle

[11] G. Haddow, J. Bullock, and D. P. Coppola, Introduction to Emergency Management, Butterworth-Heinemann, 2007.

[12] F. Sujanto, A. Ceglowski, F. Burstein, and L. Churilov, "An integrated framework for comprehensive collaborative emergency management," in Proc. CDM, 2008, pp. 127-138.

[13] T. Tao and N. Kouwen, "Remote sensing and fully distributed modeling for flood forecasting," Journal of Water Resources Planning and Management, vol. 115, pp. 809-823, 1989.

[14] eXtreme Virtual Reality (XVR). (Sep. 29, 2013). Immersive Visualization Systems. [Online]. Available: http://www.vrmedia.it/en/xvr.html

[15] ProProfs. (Sep. 29, 2013). Reporting \& Online Training Tracking System. [Online]. Available: http://www.proprofs.com/training/

[16] J. Grudin, "Turing maturing: the separation of artificial intelligence and human-computer interaction," Interactions, vol. 13, pp. 54-57, 2006.

[17] R. Kumar, "Research methodology: A step-by-step guide for beginners," Third Edition edition ed., SAGE Publications Ltd, 2010.

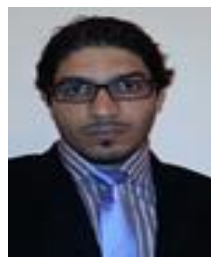

M. Hijji was born in UK, 1985. He received his BSc computer engineering, in Umm Al-Qura University, Mecca, SA, 2008, MSc in network computing, Coventry University, Coventry, UK, 2011 and he is currently a $\mathrm{PhD}$ candidate in computing and digital environment, Coventry University, Coventry, UK.

$\mathrm{He}$ worked as a teaching assistant, technical supervisor, and technical in Information Technology 